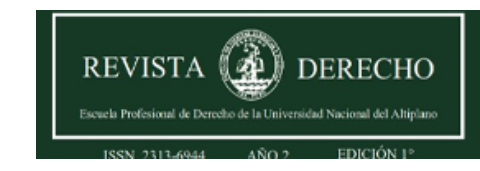

Revista de Derecho

ISSN: 2313-6944

ISSN: 2707-9651

revistaderecho@unap.edu.pe

Universidad Nacional del Altiplano

Perú

\title{
Las convenciones probatorias en el Código Procesal Penal: dificultades para su aplicación en el sistema procesal penal peruano
}

Sucari Cruz, Rolando

Las convenciones probatorias en el Código Procesal Penal: dificultades para su aplicación en el sistema procesal penal peruano

Revista de Derecho, vol. 7, núm. 1, 2022

Universidad Nacional del Altiplano, Perú

Disponible en: https://www.redalyc.org/articulo.oa?id=671870939003

DOI: https://doi.org/10.47712/rd.2022.v7i1.170

\section{(c) $(1)$}

Esta obra está bajo una Licencia Creative Commons Atribución 4.0 Internacional. 
Artículos de doctrina, análisis y crítica jurisprudencial

\title{
Las convenciones probatorias en el Código Procesal Penal: dificultades para su aplicación en el sistema procesal penal peruano
}

\author{
Evidentiary conventions in the Code of Criminal Procedure: difficulties for their application in the Peruvian \\ criminal procedural system
}

Rolando Sucari Cruz 1

Ministerio Público del Perú, Perú

rosucari@unap.edu.pe

DOI: https://doi.org/10.47712/rd.2022.v7i1.170

Redalyc: https://www.redalyc.org/articulo.oa?

https://orcid.org/0000-0003-0424-7636

Recepción: 31 Diciembre 2021

Aprobación: 03 Enero 2022

Publicación: 04 Enero 2022

\section{Resumen:}

El código adjetivo de 2004 ha incorporado la justicia penal negociada en el sistema adversarial (sistema penal acusatorio). Como una manifestación del mismo son las convenciones probatorias que brindan una solución a los intereses confrontados de las partes de forma voluntaria y consensuada, ya que opera como un mecanismo de simplificación procesal. Y ofrece ciertas ventajas: (i) las partes voluntariamente pueden solucionar sus intereses en conflicto y (ii) contribuye a la resolución pronta y eficaz del problema, esto es, celeridad y economía procesal. No obstante, se presentan dificultades que han impedido que se apliquen, tales como una regulación dispersa, asistemática y precario desarrollo a nivel de la jurisprudencia y la doctrina. De hecho, un aspecto que ha originado varios inconvenientes es sobre los límites de su aplicación u objeto sobre el que recae. Este trabajo, justamente, dilucida ese punto a partir de la revisión de la doctrina y la jurisprudencia. Las conclusiones más relevantes que pueden mencionarse son: (i) las convenciones probatorias pueden versar sobre hechos principales de la imputación, pues no se circunscriben únicamente a hechos o circunstancias accesorias y (ii) en la doctrina y la jurisprudencia se considera que las convenciones probatorias pueden recaer sobre hechos principales, pero con ciertas limitaciones, ya que a través de este mecanismo de simplificación procesal no puede determinarse la responsabilidad penal o las circunstancias modificatorias de esta.

Palabras Clave: Convenciones probatorias, hechos, jurisprudencia, responsabilidad penal.

\section{Abstract:}

The 2004 adjective code has incorporated negotiated criminal justice in the adversarial system (accusatory criminal system). As a manifestation of it are the evidentiary conventions that provide a solution to the conflicting interests of the parties on a voluntary and consensual basis, as it operates as a mechanism of procedural simplification. And it offers certain advantages: (i) the parties can voluntarily settle their conflicting interests and (ii) it contributes to the prompt and efficient resolution of the problem, i.e., procedural celerity and economy. However, there are difficulties that have prevented their application, such as a dispersed, asystematic regulation and precarious development at the level of jurisprudence and doctrine. In fact, one aspect that has given rise to several inconveniences is the limits of its application or the object on which it falls. This paper, precisely, elucidates this point based on a review of the doctrine and case law. The most relevant conclusions that can be mentioned are: (i) evidentiary conventions may deal with the main facts of the accusation, since they are not limited only to accessory facts or circumstances and (ii) in the doctrine and case law it is considered that evidentiary conventions may fall on main facts, but with certain limitations, since through this mechanism of procedural simplification criminal liability or circumstances modifying it cannot be determined.

KEYWORDS: Evidentiary conventions, facts, jurisprudence, criminal liability.

\section{NotAS DE AUTOR}

1 Abogado por la Universidad Nacional del Altiplano de Puno. Doctor en Derecho. Fiscal Adjunto Superior de la Segunda Fiscalía Superior Penal de Puno - Ministerio Público del Perú

rosucari@unap.edu.pe 


\section{INTRODUCCIÓN}

El modelo procesal que acoge el Código adjetivo de 2004 es concebido como acusatorio garantista con rasgos adversariales. Acusatorio en cuanto a la función de acusar que se encuentra separada de quien asume la función de juzgar. Garantista por cuanto el proceso penal se desarrolla apegado a las garantías constitucionales previstas en la Constitución. En este modelo — adversarial-acusatorio-, se presenta la contienda entre dos partes que asumen diferentes roles como son acusador y acusado, es dentro de esta característica adversarial donde encontramos la justicia penal negociada, ya que estos roles no necesariamente deben mantenerse confrontados, sino que pueden tolerar confluencias en beneficio mutuo, una oportunidad para tal beneficio es el establecimiento voluntario y consensuado de una convención probatoria.

Las convenciones probatorias versan sobre acuerdos a los que pueden arribar los sujetos procesales con respecto a diversos hechos o circunstancias, dándose por acreditados en el proceso y, por ende, obviando su actuación y debate contradictorio en el juicio oral. También puede producirse tal como prevé nuestra norma procesal, sobre los medios de prueba con los que se darán por acreditados ciertos hechos, sean principales o secundarios, siempre que no sean referidos a la responsabilidad penal del individuo. Es así que las convenciones probatorias son un mecanismo de simplificación procesal, respecto de la cual, es conveniente precisar que forma parte de un sistema de resolución de conflictos inmersos dentro del método autocompositivo. Sin embargo, a priori se ha concluido su escasa utilización como mecanismo que simplifique el juicio oral, dado que tiene el menor índice de aplicación, ni siquiera se ha considerado en las estadísticas de Gestión de Indicadores del Ministerio Público que se tiene a nivel nacional[i]. A diferencia de otras salidas alternativas del proceso y la investigación, como la terminación anticipada y los criterios de oportunidad. Por otro lado, tampoco aparece en el Sistema de Gestión del Poder Judicial como si ocurre con los demás mecanismos de simplificación procesal.

La regulación de este mecanismo de simplificación lo encontramos en diversos artículos del Código Procesal Penal de 2004 como el $156^{\circ}, 350^{\circ}, 352^{\circ}$ y $353^{\circ}$, en definitiva, es una regulación dispersa, asistemática, además no ha tenido mayor desarrollo doctrinario y en los escasas líneas abordadas se señala que las convenciones probatorias debe circunscribirse únicamente respecto a hechos o circunstancias accesorias y no respecto a hechos principales de la imputación, menos puede recaer sobre particularidades que puedan determinar la responsabilidad penal del imputado y circunstancias modificatorias de esta. No puede fundarse la culpabilidad o la inocencia sólo en base a lo celebrado en las convenciones probatorias. Sin embargo, resulta difícil delimitar con precisión cuáles son esas circunstancias fácticas accesorias, satélites de la imputación. Además, no se tiene límites que especifiquen cuáles serían las materias o aspectos sobre los cuales no puede recaer las convenciones probatorias, en razón a que las convenciones probatorias no pueden ser ilimitados. No puede afirmarse que solo con las convenciones probatorias pueda determinarse la responsabilidad penal. Ante ello, el presente estudio efectúa un análisis dogmático y jurisprudencial de su regulación en nuestro Código Procesal Penal en comparación con otras legislaciones, a su vez, como producto de ese trabajo se han obtenido las siguientes conclusiones: (i) las causas más importantes de su escasa aplicación es la mala técnica legislativa, (ii) la aplicación de éstas puede producirse en las diferentes etapas del proceso penal, (iii) pueden versar sobre hechos principales que estén vinculados a la estructura del tipo penal y (iv) no puede recaer sobre la responsabilidad penal, ni las circunstancias modificatorias de esta.

MARCO TEÓRICO

\subsection{OBJETO DE PRUEBA}

El objeto de la prueba es el hecho que debe verificarse y sobre el cual el juez emite un pronunciamiento. Ferrer (2007) afirma que:

La función principal del proceso judicial estriba en determinar o considerar como verdadera la alegación sobre la ocurrencia de determinados hechos a los que el Derecho vincula determinadas consecuencias jurídicas y la imposición de esas 
consecuencias a los sujetos previstos por el propio Derecho; por ello, se ha de concluir que la función del proceso es la aplicación del Derecho (p.29).

En ese sentido, podríamos referir que el demostrar la verdad de los hechos en el que se funda una pretensión procesal constituye un derecho y también es un deber de las partes. La demostración de esta verdad obviamente debe darse a través de medios que la parte considere sostendrán la credibilidad de lo alegado, en síntesis, probar significa convencer al juez sobre la certeza de la existencia de un hecho (Roxin, 2000). Así, prueba es todo aquello que pueda servir para descubrir la verdad acerca de los hechos que en el proceso son investigados y respecto de los cuales se pretende actuar la ley sustantiva (Cafferata, 2000). En ese entender, como explica Neyra (2015), etimológicamente el término "prueba" deriva del latín "probatio probationis", que a su vez deriva del vocablo probus que significa bueno, luego, lo que resulta probado es bueno, se ajusta a la realidad, y probar consiste en verificar o demostrar la autenticidad de una cosa. En consecuencia, la prueba al convertirse en un medio de comprobación y demostración de los hechos imprime objetividad a la decisión judicial.

Ahora, respecto al contenido de qué es lo que se debe probar, es decir, el objeto de prueba, podemos indicar que aquello sobre el cual recae la actividad probatoria a través de sus diversos componentes, por ende, objeto de prueba será todo aquello que sea pasible de ser probado, y de manera más específica, en el artículo $156^{\circ}$, numeral 1 del Código Procesal Penal indica que "son objeto de prueba los hechos que se refieran a la imputación, la punibilidad y la determinación de la pena o medida de seguridad, así como los referidos a la responsabilidad civil derivada del delito". También indica lo que no es objeto de prueba "las máximas de la experiencia, las leyes naturales, la norma jurídica interna vigente, aquello que es objeto de cosa juzgada, lo imposible y lo notorio".

\subsection{CONVENCIONES PROBATORIAS}

\subsubsection{DEFINICIÓN}

La figura de las convenciones probatorias ha sido dogmáticamente estudiada por diversos autores, al respecto, Ugaz (2015) refiere que las convenciones probatorias son acuerdos tomados, entre las partes en un proceso penal, los cuales pueden versar sobre hechos, circunstancias o medios de prueba, así, si la convención es respecto de los dos primeros, estos serán tenidos por ciertos en el juicio oral y, por ende, se dispensará de la carga de probarlos; en cambio, si se dispone convención respecto de la idoneidad de determinada prueba para acreditar algún hecho, su efecto será que no habrá otro medio que lo pueda probar.

Conceptualizando las convenciones probatorias dentro del rango de los hechos, Rosas (2013) refiere que son el arreglo que realizan las partes del proceso penal para dar por confirmados ciertos hechos sobre los cuales no exista discusión respecto de su ocurrencia y las circunstancias que los rodean, y que, debido a ello, no podrán ser discutidos ni debatidos en el juzgamiento. En esa misma línea, pero más delimitada en cuanto a las partes, Talavera (2009) señala que una excepción al principio de necesidad de prueba está constituida por las llamadas convenciones o estipulaciones probatorias, las misma que vienen a ser acuerdos celebrados entre el fiscal y la defensa para tener probados alguno o algunos hechos o circunstancias, así como sobre los medios de prueba que deban ser utilizados para probar determinados hechos y considera que es una expresión más de un modelo adversativo, en el cual las partes tienen una mayor presencia e intervención.

Otra acepción que encontramos respecto de las convenciones probatorias, con un mayor énfasis en el papel del juzgador es a Oré (2016) quien refiere que las convenciones probatorias son aquellos actos procesales que, previa aprobación judicial, tienen como finalidad, de un lado, dar por cierto determinados hechos sin necesidad de la correspondiente actuación probatoria y de otro, informar al juez penal que un determinado hecho se acreditará a través de un medio de prueba específico.

Finalmente, por nuestra parte, definimos a las convenciones probatorias como aquellos acuerdos a los cuales llegan los sujetos procesales a fin de concluir que determinados hechos o circunstancias no requieren de actuación probatoria, por consiguiente, las partes las dan por aceptadas y es innecesaria su debate oral. 


\subsubsection{REGULACIÓN DE LAS CONVENCIONES PROBATORIAS EN EL CÓDIGO PROCESAL PENAL}

En el Código Procesal Penal, las convenciones probatorias se regulan y establecen en diversos artículos, como el artículo $156^{\circ}, 350^{\circ}, 352^{\circ}$ y $353^{\circ}$. Los mismos que se detallan a continuación:

(i) el artículo $156^{\circ}$, si bien es cierto que no hace una mención explícita, sin embargo, de la redacción se puede inferir que se vincula con las convenciones probatorias, al respecto, se indica que "las partes podrán acordar que determinada circunstancia no necesita ser probada, en cuyo caso se valorará como un hecho notorio. El acuerdo se hará constar en el acta".

(ii) en los artículos $350^{\circ}, 352^{\circ}$ y $353^{\circ}$ se indica que las convenciones probatorias han de ser celebradas en la etapa intermedia, dentro de los diez días después de notificada la acusación. Parece que la norma solo diera a la defensa la posibilidad de proponer la celebración de convenciones probatorias mas no al fiscal, sin embargo, apelando al principio de igualdad en el proceso y la práctica -escasa, por cierto-, se advierte que en realidad cualquiera de las partes tendrá la posibilidad de proponerlas. Continuando con el desarrollo de los siguientes artículos, hacen referencia al supuesto que se dé convención probatoria, deberá ser plasmada en auto de enjuiciamiento a fin de dar conocimiento al juez penal unipersonal o colegiado que asumirá la siguiente etapa del proceso.

\subsection{3. ÁMBITO DE CELEBRACIÓN DE LAS CONVENCIONES PROBATORIAS}

\subsubsection{CONVENCIÓN SOBRE HECHOS}

La convención probatoria, tradicionalmente, es definida como un acuerdo sobre hechos. Conforme se puede apreciar del contenido de los artículos $156^{\circ}$ y $352^{\circ}$ del Código Procesal Penal, concordante con demás legislaciones a nivel latinoamericano, como el de Venezuela, Colombia o Chile, donde las convenciones tienen un mismo nivel de estudio, pero con mayor aplicación dentro de sus procesos penales. Así, las convenciones probatorias sobre hechos se representan como una herramienta que permite al juez y a las partes, limitar la prueba en determinados enunciados fácticos en aquellos casos que exista consenso entre los intervinientes sobre estos. De esta forma, el efecto de su aplicación será que se acortarán los puntos de prueba, reduciéndose el objeto probatorio exclusivamente a aquellas afirmaciones de hechos que resultan controvertidos (Cociña, 2013). De esta manera, los acuerdos de los intervinientes sobre hechos no controvertidos, al ser aprobados por el Juez, dispensan de la carga de probarlos a través de medios probatorios.

Por tanto, respecto a este tipo de convenciones, una de las partes afirma un hecho o circunstancia no controvertida por la otra parte, coincidiendo en señalar que el hecho se produjo, existiendo consenso al respecto; por tanto, optan por acordar que la circunstancia o el hecho no necesita ser probado y así lo hacen saber al juzgador, de quien se espera su aprobación.

\subsubsection{CONVENCIÓN SOBRE MEDIOS DE PRUEBA}

En nuestra legislación, conforme al artículo $350^{\circ}$ numeral 2, se prevé la convención respecto a medios de prueba, ya que el artículo citado lo expresa así “(...) Asimismo, podrán proponer acuerdos acerca de los medios de prueba que serán necesarios para que determinados hechos se estimen probados (...)”. Este agregado constituye de vital importancia en nuestro ordenamiento para la celebración de convenciones probatorias, pues al decidir respecto a qué medio de prueba será actuado para probar determinado hecho, se omite la actuación de los demás, dando así mayor celeridad al proceso a través de la actuación probatoria en juicio oral. Así, una convención probatoria respecto a medios de prueba, facilita el debate, actuando únicamente uno de los medios de prueba ofrecidos para tener o no por acreditado el hecho, debiendo el juez en virtud de la convención probatoria arribada por las partes, tenerla por admitida, ya que lo acordado por los sujetos procesales deberá actuarse y debatirse en el juicio oral. Cuando las partes optan por convenir que un solo medio de prueba de todos los ofrecidos para acreditar un hecho, sea actuado en juicio oral, los demás no serán actuados o debatidos en el juicio y, por tanto, no serán valorados por el órgano jurisdiccional. Es justamente ello lo que convierte en compleja esta clase de convención probatoria, pues la parte aportante de los medios de prueba debe escoger el que resulte más idóneo para acreditar el hecho a probar, pues podría ocurrir que a 
raíz de la convención probatoria que el que resultó elegido termine por favorecer a la contraparte (Aguirre, 2012). De esta manera, la elección del medio de prueba a actuarse en el juicio oral, se convierte entonces en una decisión estratégica.

\subsubsection{MOMENTO DE CELEBRACIÓN DE LAS CONVENCIONES PROBATORIAS}

\subsubsection{CONVENCIONES PROBATORIAS EN LA ETAPA INTERMEDIA}

En nuestra normativa procesal penal peruana, las convenciones probatorias están reguladas en la segunda etapa del proceso penal común, la denominada etapa intermedia. Se presenta luego de que el Ministerio Público ha formulado el requerimiento acusatorio conforme al artículo $349^{\circ}$ del Código Procesal Penal. Los sujetos procesales dentro de los diez días posteriores al requerimiento y por escrito, podrán proponer acuerdos, esto es, convenciones probatorias sobre hechos, circunstancias y medios de prueba que acepten. Estos, en caso se apruebe por el Juez de investigación preparatoria, se darán por acreditados, obviando su actuación probatoria en el juicio.

\subsubsection{CONVENCIONES PROBATORIAS EN LA ETAPA DE JUZGAMIENTO}

En la audiencia de juicio oral, se tiene a los alegatos de apertura como expresión de la exposición breve, de hechos, calificación jurídica y medios probatorios. Al hacerlo, se informa al juez respecto a las pretensiones procesales y como es que se acreditará a lo largo del desarrollo de la audiencia de juicio oral, este momento del juicio permite anticipar al juez los puntos en los que el contenido de la teoría del caso es controvertido y, por ende, requieren de actuación probatoria y los que no necesitan.

El artículo $372^{\circ}$ del Código Procesal Penal otorga la oportunidad para que el acusado, enterado de la acusación y la posición de su defensa e instruido de sus derechos por el juez, admita responsabilidad en el delito por el cual se le acusa, además, es responsable de la reparación civil. Para que esto sea posible, el acusado podrá requerir la momentánea suspensión de la audiencia para conferenciar con el fiscal en aras de alcanzar un acuerdo sobre la pena, si esto es logrado de manera satisfactoria se habrá declarado la conclusión del juicio, apréciese aquí el expreso reconocimiento normativo de la posibilidad de que, para lograr la culminación del proceso penal, los sujetos procesales acuerden, convengan y armonicen el quantum de la pena. Si se les permite hacer esto en juzgamiento con mayor razón se les podría permitir arribar a un acuerdo respecto a convenciones probatorias. La convención probatoria podría tener lugar al inicio, esto es, una vez desarrollado los alegatos de apertura en el juicio oral. En efecto, si una norma autoriza incorporar esta nueva oportunidad de tramitación, ello sería facultad de las partes para solicitarlas cuando lo crean conveniente, y con relación a sus intereses, redundará en beneficio de una celeridad procesal y en un juzgamiento en la menor cantidad de sesiones de audiencia, evitando las sesiones innecesarias.

Como es sabido, la realización de audiencias y, más aún, referidos en casos de mediana y alta criminalidad que involucran la concurrencia de un número considerable de órganos de prueba, así como de abundantes documentales, da lugar a que el tiempo a ser utilizado sea muy extenso. Ello, obviamente, implica diversos problemas: reprogramaciones de audiencia sin justificación, ausencia de testigos y peritos al juicio oral, reprogramaciones de audiencia por inasistencia del Fiscal, reprogramaciones por inasistencia de uno u otro abogado, pluralidad de abogados, reemplazo de un abogado particular por un defensor público o, simplemente, ocasionar incidencias para agotar a los órganos de prueba de cargo.

Estas circunstancias podrían verse aligeradas y superadas en parte, si se promoviera, utilizara, aceptara y aprobara el mecanismo procesal de las convenciones probatorias en la etapa de juzgamiento. En la jurisprudencia, como fuente de derecho, se viene practicando, así es cómo podemos apreciar en el criterio que ha sido adoptado en el Pleno Jurisdiccional Distrital de La Libertad del 19 de septiembre de 2014, en el que por unanimidad se ha acordado, que “(...) las convenciones probatorias (...) de manera excepcional también pueden ser propuestas y resueltas en la etapa de juzgamiento, previo a la actuación probatoria”. Dentro de los fundamentos que acogen esta tesis se aprecia el principio de economía procesal, por el cual es innecesaria la actuación respecto a hechos sobre los que no existe controversia entre las partes. Tal situación es mejor que ocurra en la etapa de juzgamiento donde están involucrados el Juez Penal Unipersonal o Colegiado que 
estará a cargo de realizar el juicio oral y por ende la actuación probatoria, etapa donde recaerá de manera directa las convenciones probatorias.

\subsubsection{VINCULACIÓN DEL JUEZ}

Conforme el artículo $350^{\circ}$ numeral 2 , los sujetos procesales pueden proponer los hechos que aceptan y, por consiguiente, obviaran su actuación probatoria. También pueden proponer un acuerdo respecto a los medios de prueba que serán necesarios para que determinados hechos se estimen probados. En la misma línea, a su vez, se establece que “(...) el juez, sin embargo, exponiendo los motivos que lo justifiquen, podrá desvincularse de estos acuerdos, en caso contrario, si no fundamenta especialmente las razones de su rechazo, carecerá de efecto la decisión que los desestime".

Cuando el juez de garantías aprueba o desaprueba el acuerdo aprobatorio entre las partes, da pie a que vincule al mismo o como no puede hacerlo. Ahora, el Juez de Investigación Preparatoria cuando llega a vincularse con lo acordado, lo que en verdad hace es vincular a otro juez, es decir, a quien dirige la siguiente etapa del proceso, el Juez Penal Unipersonal o Colegiado, quien deberá ceñirse al mismo, a menos que las convenciones probatorias sean celebradas ante él, ya que, en este caso, será él, quien la apruebe o no, provocando como efecto inmediato una vinculación.

\subsubsection{PARTES INTERVINIENTES}

La norma procesal señala que la celebración de convenciones probatorias solo está facultada a las partes, es decir quien asuma la defensa y quien represente al Ministerio Público; así:

\footnotetext{
Las convenciones probatorias pueden formularse a partir del concierto de voluntades entre las partes principales y adversarias a la vez, tales como el fiscal y la defensa, respecto de los hechos o pruebas relacionadas con las pretensiones penal y civil, si no hubiera actor civil constituido. Caso contrario, es decir, si la víctima se hubiera constituido en actor civil, ésta podrá formular convenciones probatorias con la defensa respecto de los hechos o pruebas relacionadas con la pretensión civil. También pueden celebrar convenciones probatorias el tercero civilmente responsable y el actor civil, respecto a hechos o circunstancias vinculados a la reparación civil. (Talavera, 2017, p.95)
}

En efecto, consideramos que todos los sujetos procesales pueden proponer convenciones probatorias, respecto de los hechos, circunstancias o medios de prueba, pues será a partir de una propuesta que se buscará el consenso para celebrar la convención probatoria.

Oré (2016) sostiene que, en el caso de las convenciones probatorias fundadas en la aceptación de los hechos, los sujetos legitimados para proponerlo están conformados por todas las partes procesales distintas al fiscal (no comprende al fiscal como sujeto legitimado), toda vez que su intervención se produce con el objeto de proponer los hechos y pruebas sobre lo que, en principio, discurrirá la actuación probatoria. Esta afirmación surge de la regulación procesal del artículo $350^{\circ}$ numeral 2 del Código Procesal Penal, pues allí se establece que luego de correr traslado con la acusación, los demás sujetos procesales podrán proponer los hechos que aceptan y que el juez dará por acreditados, obviando su actuación probatoria. Sin embargo, si efectuamos una interpretación sistemática de la norma procesal con el artículo $156^{\circ}$ numeral 3 , establece que las partes podrán celebrar acuerdos sobre las circunstancias, en cuyo caso no será necesario la actuación probatoria, dejando claramente abierta la posibilidad de iniciativa a cualquiera de las partes en la celebración de convenciones probatorias.

Si se ha celebrado un acuerdo acerca de hechos o circunstancias o sobre medios de prueba como contempla la norma, ineludiblemente, como fue señalado anteriormente, su observancia será obligatoria para las partes, siempre que haya sido sometido a la aprobación del juez (exista revisión del cumplimiento de todas las garantías fundamentales). Ya que este acuerdo es la exteriorización de la confluencia de voluntades de las partes como son el Ministerio Público, defensa y demás partes que intervengan en el proceso; caso contrario, la falta de consentimiento de algunas de las partes es inválido.

\subsection{HECHOS EN EL PROCESO PENAL}

El hecho es todo lo que acontece y puede ser percibido por los sentidos. El hecho se refiere a sucesos o situaciones reales, dice cuándo, dónde y de qué modo ha ocurrido ciertos eventos en la realidad. 
El hecho puede ser una entidad física, estática o dinámica, a veces perceptible por los sentidos cuando se exterioriza y, a veces, solo perceptible con la ayuda de instrumentos y manipulaciones científicas. Estos hechos serán sucesos o acontecimientos generados, con o sin la intervención del hombre, y a su vez, tales hechos pueden o no generar consecuencias jurídicas; y, aquellas que generen consecuencias jurídicas se le denominará hechos jurídicos (Vidal, 2002). Por tanto, el hecho tendrá trascendencia en el mundo del derecho, cuando el ordenamiento jurídico así lo ha previsto dentro de su normatividad y será sobre estos que girará la prueba y se situará la decisión judicial.

En consecuencia, en el proceso penal como bien refiere Ugaz (2015) "El hecho es la enunciación de un fenómeno histórico, no el fenómeno empírico que es enunciado. Las circunstancias de derecho son en realidad conjeturas acerca de la situación de hechos, es decir, hechos afirmados como verdaderos" (p.67).

\subsection{CLASIFICACIÓN DE HECHOS}

Los hechos sobre los que gira el proceso pueden ser divididos o clasificados de diversas maneras, para el presente estudio, los dividiremos en principales y secundarios.

\subsubsection{HECHOS PRINCIPALES}

Constituyen el centro de la imputación, a ellos la norma los califica como relevante, constitutivo, extintivo, impeditivos o modificativos, es decir, como punto de referencia de los efectos que la norma misma define, son el presupuesto de la consecuencia jurídica (Taruffo, 2011).

Desde el punto de vista del Derecho Penal, se puede decir que el hecho principal es el hecho concreto descrito en la Ley como delito. Se identifica con la afirmación de los hechos que realizan los elementos del tipo penal y constitutivos de la imputación. En este último sentido, el objeto de la prueba en el proceso penal puede identificarse con los hechos que constituyen el contenido mismo de la imputación; por ejemplo, la acción de tirar del gatillo y como a consecuencia del mismo obtener la muerte de la víctima para configurar el delito de homicidio, entre otros. A esto se le llama objeto principal o general de la prueba, que es el hecho del delito y puede comprobarse directamente (Ugaz, 2015).

\subsubsection{HECHOS SECUNDARIOS}

Los hechos secundarios o también llamados accesorios:

Son aquellos que, sin ser sustancialmente constitutivos, extintivos modificativos o impeditivos de la relación jurídica pueden afectar directa o indirectamente la existencia o inexistencia de hechos principales. En resumidas cuentas, los hechos secundarios pueden potenciar o consolidar la afirmación o negación del hecho jurídico principal, contribuyendo de esta manera con acreditar la veracidad del hecho jurídico principal (Taruffo, 2010, p.120).

Si bien el punto central de la prueba versa sobre el hecho de la imputación, es decir, el hecho principal, es de reconocerse que no siempre se cuenta con los medios que nos permiten apoyarnos solo en ella, por tanto, es necesario recurrir a demás hechos que rodean al principal, es decir, abarcan hechos accesorios y circunstanciales, que apoyen y den fidelidad respecto del punto central de imputación.

Así, tal como sostiene Taruffo (2010):

De los hechos secundarios se puede extraer inferencias relativas a la verdad o falsedad de enunciados sobre hechos principales, son indicios o hechos base de presunciones. (p.233)

Es más, debe tenerse presente que por lo general la comprobación directa del hecho delictuoso no es posible, por lo que debe recurrirse a diversas circunstancias que convienen a esta situación y que sirven para determinar la veracidad de la afirmación sobre la existencia o inexistencia de un hecho fundamental; circunstancias que deben comprobarse (Guevara, 2018). Así, por ejemplo, es objeto de prueba todo aquello que, sin ser necesariamente delito, tiene vinculación objetiva con él, como la vestimenta del agresor al momento de cometer el homicidio, es relevante para establecer su identificación (Morales, 2004). Como se podrá denotar, ahí es donde radica la importancia de los hechos secundarios, son los que componen la situación alegada o están vinculadas a ellas.

\subsection{RESPONSABILIDAD PENAL}


La responsabilidad penal es consecuencia de un hecho ejecutado, sin identificarla con ninguno de los componentes del sistema de la teoría del delito, todos los cuales, lógicamente, asumen la condición de presupuestos de aquélla. Entre tales planteamientos, destaca, en primer término, un criterio que concibe la responsabilidad como la obligación que pesa sobre el autor de un delito de soportar la pena prevista para el evento de su comisión (Jiménez, 1956). Así, se entiende a la responsabilidad penal como una carga que se impone a quien ha ejecutado un hecho reprimido por la norma. No obstante, debe tenerse claro que para arribar a dicha consecuencia debe contarse con la concurrencia de otros elementos como son la teoría del delito, las condiciones objetivas de punibilidad y la valuación de excusas legales absolutorias.

También como consecuencia del delito, pero con un carácter preponderantemente subjetivo, conciben la responsabilidad penal quienes la definen como aquella situación en que se encuentra el delincuente de tener que enfrentar las consecuencias jurídicas que la ley prevé para la ejecución del hecho. Este criterio, en realidad, no constituye sino una variante del anterior, pues enfatiza, más que la obligación en sí, la situación que afecta a quien tiene el deber de cumplirla (Ramírez, 1986).

Siguiendo en esta línea de acepciones, tenemos aquellas que entienden a la responsabilidad penal como "La consecuencia de reunirse en un sujeto todas las circunstancias que hacen de él un delincuente, lo que le impone la necesidad de soportar todas las sanciones que la ley tiene previstas para sus transgresores" (Novoa, 2005, p.419). En un sentido similar, se contempla a la responsabilidad penal como "La situación jurídica en que se encuentra la persona obligada por la ley a someterse a la pena en ella prevista, que los órganos del Estado reciben la orden de imponerle" (Etcheverry, 1998, p.9).

De lo referido, se puede concluir a la responsabilidad penal como la consecuencia jurídica de la comisión de un delito que recae sobre quien materializó la conducta antijurídica determinada por Ley.

1.6. CIRCUNSTANCIAS MODIFICATORIAS DE LA RESPONSABILIDAD PENAL

Las circunstancias modificativas de la responsabilidad criminal son hechos que rodean al delito o circunstancias del autor de los hechos, que provocan que la pena a aplicar se module de una determinada forma.

Desde el punto de vista material, las circunstancias, Cerezo Mir (2005) afirma:

Consisten en un hecho, relación o dato concreto, que el legislador tiene en cuenta para los efectos de graduar la responsabilidad penal. El componente fáctico de esta clase de circunstancias, en efecto, no siempre está relacionado con la conducta delictiva, ni consiste en un acto voluntario de las personas que toman parte en su ejecución, sino que en muchos casos está constituido por una situación o relación preexistente al delito, o incluso posterior a él; y, en general, por cualquier antecedente que tenga la virtud de traducir los propósitos de concreción de la responsabilidad penal. (p.104)

Las circunstancias modificatorias pueden consistir tanto en hechos materiales, como en situaciones de carácter personal; siendo, precisamente, estos hechos o situaciones los que en esencia constituyen cada circunstancia modificatoria, en tanto que es sobre estos que ha de recaer el conocimiento allí exigido. El elemento esencial o constitutivo de una circunstancia modificatoria, en consecuencia, posee mayor amplitud que aquel que sirve de base al delito. Es efectivo que estas circunstancias no se proyectan sobre el ámbito de la infracción delictiva, sino sobre el de sus consecuencias. De ahí que estas circunstancias están llamadas a cumplir un rol que nada tenga que ver con la configuración del hecho punible y que, en el plano sistemático, sólo proyecten su influencia a nivel de la pena, único instrumento de concreción de la responsabilidad criminal. En consecuencia, las circunstancias modificatorias de responsabilidad penal son aquellos hechos, situaciones o datos, ajenos a la estructura del tipo, a los cuales la ley confiere la virtud de servir como instrumento de medición de la intensidad que ha de revestir la pena en cada caso concreto (Rodríguez, 2011) 


\title{
II. RESULTADOS
}

\subsection{Revisión de posiciones doctrinarias que señalan que las convenciones probatorias sólo pueden versar sobre hechos secundarios}

El problema con las convenciones probatorias es con relación al límite o condiciones dentro de los cuales deben operar las mismas. En la doctrina se ha establecido que las convenciones probatorias únicamente pueden celebrarse respecto a hechos secundarios.

Respecto a la extensión de la convención probatoria San Martín (2020) señala:

\begin{abstract}
En cuanto a la extensión de la convención probatoria. Se refiere sólo a hechos secundarios y a las denominadas circunstancias, pues si no se acude a la terminación anticipada y en tanto el juicio contradictorio exige que la construcción de los hechos se verifique de un modo cognoscitivo y no meramente convencional, no se pueden "convenir" sobre la existencia del hecho punible y la responsabilidad penal del imputado, dejándose a la actuación probatoria aspectos referidos a grado del delito, participación, circunstancias modificativas". (p.848)
\end{abstract}

En esa perspectiva, Ugaz (2015) con la finalidad de delimitar los alcances de la convención probatoria, sostiene que el hecho sobre el que recae el acuerdo o su aceptación está conformado por el "hecho secundario", es decir, por aquellos hechos accesorios, circunstanciales o periféricos. Continúa el mismo autor indicando que, si bien no se desprenden directamente del supuesto de hecho contenido en la norma jurídica, mantienen una vinculación indirecta con ella, mediante el razonamiento inferencial.

\subsection{Revisión de posiciones doctrinarias que no precisan si las convenciones probatorias solo pueden versar sobre hechos secundarios, o también respecto a hechos principales}

En ese sentido, Oré (2016) al abordar el objeto de las convenciones probatorias refiere que:

El artículo 156.3 del Código Procesal Penal de 2004 ha prescrito que la convención probatoria recaerá sobre "determinadas circunstancias", en realidad está referido a los hechos que sustentan la pretensión penal o la pretensión civil, o los medios de prueba que serán necesarios para que determinados hechos se estimen probados” (p.448).

El autor señalado, precisa que los hechos que conforman el objeto de la convención probatoria no deben suponer, en ningún caso, el cese del proceso penal. De lo contrario, la formulación de la convención probatoria se extralimitaría, con el riesgo de generar supuestos de culminación anticipada del proceso (Oré, 2016). De lo postulado por el autor mencionado no se advierte que las convenciones probatorias recaigan sólo sobre hechos accesorios, sino menciona que está referido a los hechos que sustentan la pretensión penal.

\subsection{Revisión de posiciones jurisprudenciales que señalan que las convenciones probatorias no pueden versar sobre la responsabilidad penal y sus circunstancias modificatorias}

La Corte Suprema (2010) al abordar las convenciones probatorias, no precisa si esta puede recaer sobre hechos principales o únicamente sobre hechos secundarios, pero del fundamento citado se infiere que se enmarca sobre todas las proposiciones fácticas limitándose únicamente respecto a la aceptación de la responsabilidad.

OCTAVO.- Que dicho precepto legal regula los acuerdos probatorios de los sujetos procesales referidos a los convenios de las partes sobre determinados hechos, siempre que no se acepte responsabilidad, pues si se admiten pactos sobre la ocurrencia del hecho punible y responsabilidad del imputado, involucraría aceptar preacuerdos con la finalidad de poner 
fin anticipadamente al proceso. De esta manera se sustrae la controversia, en cuanto a esos hechos aceptados, y el Juez ya no realizará actividad probatoria al respecto, debiendo tenerlo por acreditado, siempre que se llegue al juicio oral -dentro de la audiencia preliminar de control de la acusación de conformidad con el inciso seis del artículo trescientos cincuenta y dos del Código Procesal Penal-, que es donde tiene aplicación. Asimismo, esta disposición regula los acuerdos de las partes procesales respecto a determinados medios probatorios para demostrar determinados hechos, lo que limitará la actuación probatoria en el contradictorio sólo a la actuación de esas instrumentales. (Casación Nº 12-2010-Huara, f.j. 8).

\section{DISCUSIÓN}

Ante la imposibilidad de obtención de estadísticas de Gestión de Indicadores del Ministerio Público y del Sistema de Gestión del Poder Judicial, dado que no están incorporados en sus sistemas, se ha efectuado la revisión personal de las actas del registro de audiencias. Se advirtió que las convenciones probatorias no cumplen su función de simplificar el juicio oral, por su escasa aplicación en el proceso penal. De las tres actas de registro de audiencia analizadas donde se utilizó el mecanismo procesal de las convenciones probatorias en diferentes etapas del proceso, notamos que se aplicó sobre los hechos. En efecto, revisando el contenido de las actas de registro de audiencias expediente $\mathrm{N}^{\circ}$ 0589-2019-80-2101-JR-PE-02 y expediente $N^{\circ}$ 02725-2019-43-2101-JR-PE-02, actas del Segundo Juzgado de Investigación Preparatoria de Puno, se establecieron convenciones probatorias respecto al Informe Pericial Forense de Drogas, donde se concluye que la muestra analizada corresponde a Cannabis Sativa (Marihuana), que evidencia que el informe pericial se refiere a un hecho principal, esto es, transportar marihuana al momento de la intervención policial.

El otro caso de las convenciones probatorias se dio en la etapa del juicio oral a través del Segundo Juzgado Unipersonal de San Román-Juliaca de la Corte Superior de Justicia de Puno -Índice de registro de audiencia del expediente $N^{\circ}$ 00201-2014-37-2111-JR-Pr-02 del Segundo Juzgado Unipersonal de San Román Juliaca 2014- Allí la convención probatoria fue sobre certificado médico legal, que diagnosticaba traumatismo craneoencefálico moderado, edema cerebral fractura de base de cráneo temporal izquierdo y politraumatismo. Concluyendo que los hechos que causaron son las lesiones producidas por puñete, patadas y objeto contuso. Se le otorgó una atención facultativa de 07 días y una incapacidad médico legal de 35 días. Aquí el objeto de la convención probatoria recae sobre un hecho directo o hecho principal respecto al delito de lesiones, esto es las agresiones inferidas mediante puñete, patadas y objeto contuso que se encuentran descritas en el certificado médico legal, como aparece de los hechos postulados por el Ministerio Público, según el requerimiento acusatorio[ii]:

(i) Circunstancias concomitantes.- Cuando el agraviado ingresó a su inmueble y se disponía sacar las rampas, los denunciados ingresaron, sin darle la oportunidad de poder pedir auxilio, agarrando al agraviado de los pies, mientras que otro le sujetaba de la ropa, propinándole golpes en la cabeza, refiriéndole que lo matarían, siendo que el agraviado pese a haberse defendido con sus puños y pies, los denunciados lograron reducirlo, debido a que la persona de JHONY TICONA SARAVIA le propinó un golpe entre la nariz y el ojo izquierdo con un objeto contundente, dejando al agraviado inconsciente, circunstancias en que fue acudido por su hijo de nombre Edder Fernando Castañeda Castillo, quien también fue golpeado, siendo este el motivo por el cual los denunciados dejaron de ejecutar su cometido de matar al agraviado.

(ii) Circunstancias posteriores.- El agraviado Eladio Castañeda Calla, es atendido por el medico Dionisio Duran Roque quien le expide certificado médico No 0495685 diagnosticando traumatismo craneoencefálico moderado, edema cerebral, fractura de base de cráneo temporal izquierdo, fractura de huesos propios de la nariz, trauma ocular izquierdo, politraumatismo, lo que es presentado al Médico Legista Wilber Wilar Eyzaguirre quien prescribe Atención facultativa: 07 siete, e incapacidad médico legal de (35) treinta y cinco días.

Para establecer, si este es un hecho principal o no, Taruffo (2011) y Gascón (2012) señalan:

Debe existir coincidencia entre el objeto del medio de prueba y el hecho principal; el medio de prueba será directo cuando su objeto coincide con el hecho principal; mientras que será indirecto cuando el objeto de prueba recae sobre un hecho diferente (p.445). 
La convención probatoria se realizó sobre el certificado médico legal que denota la existencia de conexión directa con el hecho a probar: agresiones físicas -hecho principal-. Si se revisan las proposiciones fácticas postuladas por el Ministerio Público, se tiene que el imputado, el día 15 de agosto de 2013, causó lesiones mediante puñete, patadas y objeto contuso, por ello, al agraviado se le otorgó una atención facultativa de 07 días y una incapacidad médico legal de 35 días. Con tal antecedente, queda expuesto que no que existe ningún límite para que las convenciones probatorias, puedan recaer sobre hechos principales, más aún como señala Taruffo la distinción entre hechos principales y hechos secundarios no está siempre clara y, en cualquier caso, representa únicamente un aspecto de un problema más complejo.

Por ello, postulo que el referido mecanismo procesal únicamente no puede versar sobre la responsabilidad penal del imputado, es decir, sobre la culpabilidad o inocencia del investigado -de efectuarse la convención probatoria sobre ello implicaría la conclusión del proceso- y las circunstancias modificatorias de esta. Pues el imputado goza de la protección por la garantía constitucional de la prohibición de la autoincriminación, por consiguiente, no se podrá condenar a una persona con el mérito de su propia declaración. Fijar la responsabilidad penal de un hecho delictivo requiere la corroboración con otros medios de prueba para emitir una decisión final.

Respecto a las circunstancias modificatorias de la responsabilidad penal, los jueces tienen la facultad exclusiva de determinar dichas circunstancias, esto es, calificar las atenuantes, agravantes de la responsabilidad. Aunque en el derecho comparado, concretamente en Chile, el Fiscal Nacional planteó criterios de actuación en la audiencia del juicio oral dirigido a los Fiscales regionales, adjuntos, asesores jurídicos y abogados ayudantes del fiscal, donde se establece la posibilidad de celebrar convenciones probatorias, respecto a circunstancias modificatorias de la responsabilidad penal[iii].

\section{CONCLUSIONES}

La escasa aplicación de las convenciones probatorias responde a la mala técnica legislativa conforme al Código Procesal Penal; por ello, debe modificarse su regulación de forma sistemática en un solo capítulo donde se encuentre la definición, procedimiento y límites de las convenciones probatorias.

La aplicación de las convenciones probatorias puede darse en las diferentes etapas del proceso penal.

Las convenciones probatorias pueden versar sobre hechos principales que estén vinculados a la estructura del tipo penal.

Las convenciones probatorias no pueden ser ilimitadas. Ello significa que no puede versar ni sobre la responsabilidad penal, ni sobre las circunstancias modificatorias de la responsabilidad penal.

\section{REFERENCIAS BIBLIOGRÁFICAS}

Aguire Chumbimuni, J. (2012). Convenciones o estipulaciones probatorias y su aplicación en el Perú: Un estudio dogmático empírico. Ius et praxis, 187-202. Obtenido de Foro jurídico: http://revistas.pucp.edu.pe/index.php /forojuridico/article/view/13786

Cafferata Nores, J. (2000). La prueba en el proceso penal. Buenos Aires: Depalma.

Cancino Muñoz y Méndez Corvalán (2020) Tesis titulada Convenciones probatorias: aplicación, alcances y límites en el sistema procesal chileno, para optar grado de licenciado en ciencias jurídicas y sociales.

Casación, N 12-2010-Huaura (Corte Suprema de Justicia de la República del Perú 2010).

Cerezo Mir, J. (2005). Derecho penal español. Parte general. Madrid: Tecnos.

Claus, R. (2000). Derecho procesal penal. (G. Cordoba, \& D. Pastor, Trads.) Buenos Aires: Editores del Puerto. 
Cociña Cholaky, M. (2013). La dinámica entre la búsqueda de la verdad y las convenciones probatorias en el proceso penal. Revista de estudios de la jusiticia, 137-160. Obtenido de http://web.derecho.uchile.cl/cej/rej18/COCIN A_11.pdf

Etcheverry, A. (1998). Derecho penal. Parte general. Santiago de Chile: Editorial Jurídica de Chile.

Ferrer Beltrán, J. (2007). La valoracion racional de la prueba. Madrid: Marcial Pons.

Gascón, M. (2012). Cuestiones probatorias. Bogotá: Universidad Externado de Colombia.

Índice de registro de audiencia, Nº0201-2014-37-2111-JR-Pr-02 (Segundo Juzgado Unipersonal de San Román Juliaca 2014).

Índice de registro de audiencia, $\mathrm{N}^{\circ}$ 0586-2019-80-2101-JR-PE-02 (Segundo Juzgado de Investigación Prepratoria de Puno 2019).

Instrucción general que imparte criterio de actuación sobre la audiencia de preparación del juicio oral, Oficio $\mathrm{FN} \mathrm{N}^{\circ}$ 284/2010 (Fiscalía Ministerio Público de Chile 2010).

Jiménez de Asúa, L. (1956). Tratado de derecho penal. Buenos Aires: Lozada.

Morales Vargas, A. (2004). Guía de actuaciones para la aplicación del nuevo codigo de procedimiento penal. Proyecto de apoyo a la reforma del nuevo código de procedimiento penal. Obtenido de Arturoyanezcortez: http://www.proce dimientopenal.com.bo/coment-casos-practicos/art_173.htm

Morales Vargas, A. (2018). Las convenciones probatorias en el proceso penal peruano, análisis para su eficaz aplicación en el marco de la justicia penal negociada. Lambayeque: repositorio UNPRG (Tesis de grado).

Neyra Flores, J. A. (2015). Tratado de Derecho procesal penal. Lima: Idemsa.

Novoa Monreal, E. (1985). Curso de Derecho Penal Chileno. Santiago de Chile: Editora jurídica de Chile.

Oré Guardia, A. (2016). Derecho Procesal Peruano. Lima: Gaceta Jurídica.

Ramírez Gronda, J. (1986). Diccionario jurídico. Buenos Aires: Heliasta.

Rodríguez Collao, L. (2011). Naturaleza y fundamento de las circunstancias modificatorias de la responsabilidad criminal. Obtenido de scielo.conicyt.cl: https://scielo.conicyt.cl/scielo.php?script=sci_arttext\&pid=S0718-68 512011000100011\#footnote-32830-14

Rosas Yataco, J. (2013). Tratado de Derecho Procesal Penal (Vol. II). Lima: Idemsa.

San Martin Castro, C. (2020). Derecho procesal penal lecciones. Lima: INPECCP.

Talavera Elguera, P. (2009). La prueba en el nuevo proceso penal: Manual del derecho probatorio de la valoración de las pruebas en el proceso penal común. Lima: AMAG - Cooperación Alemanda al desarrollo.

Talavera Elguera, P. (2017). La prueba penal. Lima: Instituto Pacífico.

Taruffo, M. (2010). El Juez y la construcción de los hechos. Madrid: Marcial Pons.

Taruffo, M. (2011). La prueba de los hechos. Madrid: Trotta.

Ugaz Zegarra, F. (2015). Las convenciones probatorias: Aspectos esenciales y prácticos de una novísima institución. Obtenido de www.fuzfirma.com: https://www.fuzfirma.com/pubpdf/5c5d4c74a80457fb001b5748a967ecc4. pdf

Vidal Ramírez, F. (2002). El acto jurídico. Lima: Gaceta jurídica.

\section{Notas}

[i]Elaborado en una edición especial a 10 años de vigencia del Código Procesal Penal en Distrito Judicial de Puno en el mes de octubre de 2019.

[ii]Proposiciones fácticas postuladas en el requerimiento acusatorio del Caso № 2706124502-2013-1622-0 de la Segunda Fiscalía Provincial Penal Corporativa de San Román-Juliaca, -tercer despacho-. 
Revista de Derecho, 2022, vol. 7, núm. 1, ENero-Julio, ISSN: 2313-6944 / 2707-9651

[iii]Eso sucedió en el marco de lo establecido en oficio FN N $284 / 2010$, instrucción general que imparte criterios de actuación sobre la audiencia de preparación del juicio oral, 31 de mayo de 2010, citada en la tesis elaborada por Daniel Cancino Muñoz y Eduardo Méndez Corvalán. 